\title{
Towards automated spectroscopic tissue classification in thyroid and parathyroid surgery
}

Citation for published version (APA):

Schols, R. M., Alic, L., Wieringa, F. P., Bouvy, N. D., \& Stassen, L. P. S. (2017). Towards automated spectroscopic tissue classification in thyroid and parathyroid surgery. International Journal of Medical Robotics and Computer Assisted Surgery, 13(1), [e1748]. https://doi.org/10.1002/rcs.1748

Document status and date:

Published: 01/03/2017

DOI:

10.1002/rcs.1748

Document Version:

Publisher's PDF, also known as Version of record

Document license:

Taverne

Please check the document version of this publication:

- A submitted manuscript is the version of the article upon submission and before peer-review. There can be important differences between the submitted version and the official published version of record.

People interested in the research are advised to contact the author for the final version of the publication, or visit the DOI to the publisher's website.

- The final author version and the galley proof are versions of the publication after peer review.

- The final published version features the final layout of the paper including the volume, issue and page numbers.

Link to publication

\footnotetext{
General rights rights.

- You may freely distribute the URL identifying the publication in the public portal. please follow below link for the End User Agreement:

www.umlib.nl/taverne-license

Take down policy

If you believe that this document breaches copyright please contact us at:

repository@maastrichtuniversity.nl

providing details and we will investigate your claim.
}

Copyright and moral rights for the publications made accessible in the public portal are retained by the authors and/or other copyright owners and it is a condition of accessing publications that users recognise and abide by the legal requirements associated with these

- Users may download and print one copy of any publication from the public portal for the purpose of private study or research.

- You may not further distribute the material or use it for any profit-making activity or commercial gain

If the publication is distributed under the terms of Article $25 \mathrm{fa}$ of the Dutch Copyright Act, indicated by the "Taverne" license above, 


\section{Towards automated spectroscopic tissue classification in thyroid and parathyroid surgery}

\author{
Rutger M. Schols ${ }^{1,2 *}$ \\ Lejla Alic ${ }^{2}$ \\ Fokko P. Wieringa ${ }^{2,3}$ \\ Nicole D. Bouvy ${ }^{1}$ \\ Laurents P. S. Stassen ${ }^{1}$ \\ ${ }^{1}$ Department of Surgery, Maastricht \\ University Medical Center \& NUTRIM \\ School for Nutrition, Toxicology and \\ Metabolism, Maastricht University, \\ Maastricht, The Netherlands \\ 'van't Hoff Program on Medical \\ Photonics, Netherlands Organization \\ for Applied Scientific Research TNO, \\ Delft, The Netherlands \\ ${ }^{3}$ Faculty of Health, Medicine and Life \\ Sciences, Maastricht University, \\ Maastricht, The Netherlands \\ *Correspondence to: Rutger M. \\ Schols, Department of Surgery, \\ Maastricht University Medical Center \\ \& NUTRIM School for Nutrition, \\ Toxicology and Metabolism, \\ Maastricht University, P. Debyelaan \\ 25, 6229 HX Maastricht, The \\ Netherlands. \\ E-mail: rutgermschols@hotmail.com
}

\begin{abstract}
Background In (para-)thyroid surgery iatrogenic parathyroid injury should be prevented. To aid the surgeons' eye, a camera system enabling parathyroid-specific image enhancement would be useful. Hyperspectral camera technology might work, provided that the spectral signature of parathyroid tissue offers enough specific features to be reliably and automatically distinguished from surrounding tissues. As a first step to investigate this, we examined the feasibility of wide band diffuse reflectance spectroscopy (DRS) for automated spectroscopic tissue classification, using silicon (Si) and indiumgallium-arsenide (InGaAs) sensors.
\end{abstract}

Methods DRS (350-1830 nm) was performed during (para-)thyroid resections. From the acquired spectra 36 features at predefined wavelengths were extracted. The best features for classification of parathyroid from adipose or thyroid were assessed by binary logistic regression for Si- and InGaAs-sensor ranges. Classification performance was evaluated by leave-one-out crossvalidation.

Results In 19 patients 299 spectra were recorded (62 tissue sites: thyroid $=23$, parathyroid $=21$, adipose $=18$ ). Classification accuracy of parathyroid-adipose was, respectively, 79\% (Si), 82\% (InGaAs) and 97\% (Si/InGaAs combined). Parathyroid-thyroid classification accuracies were 80\% ( $\mathrm{Si}$ ), 75\% (InGaAs), 82\% ( $\mathrm{Si} / \mathrm{InGaAs}$ combined).

Conclusions Si and InGaAs sensors are fairly accurate for automated spectroscopic classification of parathyroid, adipose and thyroid tissues. Combination of both sensor technologies improves accuracy. Follow-up research, aimed towards hyperspectral imaging seems justified. Copyright (C) 2016 John Wiley \& Sons, Ltd.

Keywords diffuse reflectance spectroscopy; thyroid and parathyroid surgery; automated tissue classification; parathyroid; thyroid; adipose tissue

\section{Introduction}

To perform safe and efficient thyroid and parathyroid surgery, a high level of surgical skills is required together with understanding of natural variations in head and neck anatomy (e.g. thyroid, parathyroid, lymph nodes, and recurrent laryngeal nerves). Detecting the small sized parathyroid glands and 
performing re-operative thyroid surgery can be especially challenging and time consuming. This visual task can be even more challenging due to anatomical variations in location, especially for the lower parathyroid glands (1). During these complicated surgical procedures iatrogenic injury to the parathyroid glands may occur (2). In a retrospective analysis of 5104 primary and 685 secondary thyroidectomies, temporary hypocalcaemia associated with hypoparathyroidism occurred in respectively $7.1 \%$ and $5 \%$ of cases (permanent in $1.8 \%$ and $2.5 \%$ ). The rate of permanent complications was found to be significantly higher in re-operative surgery (3). Intraoperative identification of parathyroid glands before removal of the thyroid gland is of great importance to prevent these complications. Therefore, a tool for improved intraoperative parathyroid gland detection is desirable. Exploring the capabilities of spectroscopy beyond the limitations of the human eye offers a possible roadmap towards such a tool.

Several innovative optical techniques have been under investigation for their potential in differentiating benign from malignant cells in thyroid and parathyroid specimens: multispectral image analysis $(4,5)$, Raman spectroscopy (6) and elastic scattering spectroscopy (7). Fluorescence imaging after peripheral infusion of aminolevulinic acid $(8,9)$ or methylene blue $(10)$ is reported for intraoperative detection of parathyroid adenomas. In addition, near-infrared auto-fluorescence incorporates potential for real-time parathyroid tissue localization (11). Furthermore, optical coherence tomography is reported as a tool for parathyroid gland identification $(12,13)$.

For color vision, the human eye contains only blue, green and red cones, which also partly overlap in sensitivity (poor channel separation). Yet, the trained human eye can discern quite subtle color differences within the visible range (400-780 nm). Normal surgical video cameras mimic human vision and also just capture red, green and blue light. Hyperspectral imaging, however, discerns a multitude of well-separated spectral bands for each pixel, including the near-infrared range, which is (by definition) invisible to the human eye. Since aerospace science already routinely combines hyperspectral camera technology with pre-acquired reference-library spectra recorded on the earth surface, to generate satellite images for discovering places of interest, for example, agricultural purposes and military and homeland security applications, we reasoned this technique might also hold potential for image-guided surgery (14). Although hyperspectral imaging is still far from being a routine surgical tool, it has already shown potential for noninvasive intraoperative assessment of tissue oxygen saturation $(15,16)$, for intraoperative enhancement of anatomical structures $(17,18)$ and for intraoperative tumor detection (19). Medical hyperspectral imaging-systems typically use silicon ( $\mathrm{Si}$ ) and occasionally indium gallium arsenide (InGaAs) camera chips. The wavelength range $400-1000 \mathrm{~nm}$ is covered by $\mathrm{Si}$, whereas InGaAs is typically sensitive in the 900-1700 nm wavelength region (and depending on chip composition even up to $2500 \mathrm{~nm}$ ) (14).

Diffuse reflectance spectroscopy (DRS) was studied for tissue differentiation as basis for a feedback system to enhance nerve preservation in oral and maxillofacial surgery (20), in head and neck surgery and in carpal tunnel release surgery (21). DRS has, however, not yet been studied for thyroid or parathyroid differentiation.

Nachabé et al. $(22,23)$ showed the benefit of extending visualization 'beyond silicon' up to a wavelength of $1600 \mathrm{~nm}$, providing additional information regarding tissue concentrations of the biological chromophores water and lipid.

The present translational study is a first fibre-optic spectrometric exploration with the ultimate long-term goal of obtaining parathyroid gland-specific spectral signatures as a basis for further research on image enhancement. In vivo, wide band $(350-1830 \mathrm{~nm})$ diffuse reflectance spectra of human thyroid, parathyroid and surrounding adipose tissue were collected and assessed for the presence of endogenous contrasts that might enable future tissue-specific contrast enhancement. Therefore we applied tissue classification using spectral features that are largely independent of signal intensity using a previously reported approach (21).

\section{Materials and methods}

All in vivo data acquisition was performed at the Surgery Department of Maastricht University Medical Center (MUMC, Maastricht, The Netherlands) during thyroid and parathyroid surgery (surgeon N.D.B.). Prior to measurements, the local institutional review board of Maastricht University Medical Center (registration number METC 10-4-035) granted approval and preoperative written informed consent was obtained from all patients.

\section{Material}

Diffuse reflectance spectra were acquired using custom developed ETO-sterilized disposable optical fibre probes (TNO, Eindhoven the Netherlands and Light Guide Optics, Rheinbach Germany), a modified Xenon light source (D-light C, Karl Storz, Tuttlingen Germany), and a spectrometer (Analytical Spectral Devices, Inc., Colorado USA) covering the range $350-1830 \mathrm{~nm}$. The spectrometer is equipped with two sensor technologies: a silicon ( $\mathrm{Si}$ ) based sensor and an indium gallium arsenide (InGaAs) based sensor. The cross-over point between 
these sensors is at $1000 \mathrm{~nm}$. The fibre probe is the medium to transport light from source to tissue, and to transport reflected light from tissue to spectrometer. The system was installed on a compact trolley to facilitate in vivo tissue data acquisition during routine surgery. The setup was tested and approved according to the essential requirements of IEC 60601-1 to assure patient safety. The equipment has previously been described in more detail (24).

Figure 1 shows the fibre probe tip composed of eight optical fibres: one central receiving fibre (400 um diameter, NA $0.22 \pm 0.02$ ) and seven illuminating fibres $(300 \mu \mathrm{m}$ diameter, NA $0.22 \pm 0.02)$. The rigid stainless steel probe tip has a $2 \mathrm{~mm}$ diameter and a length of $10 \mathrm{~mm}$. The remaining length of the sterile fibre probe is highly flexible.

\section{In vivo data acquisition}

During parathyroid and thyroid resections, in vivo wide-band diffuse reflectance spectra $(350-1830 \mathrm{~nm}$, $1 \mathrm{~nm}$ spectral resolution) were collected. For each tissue type, five spectra per site (taking $30 \mathrm{~s}$ per site) were acquired, covering at least one site per tissue

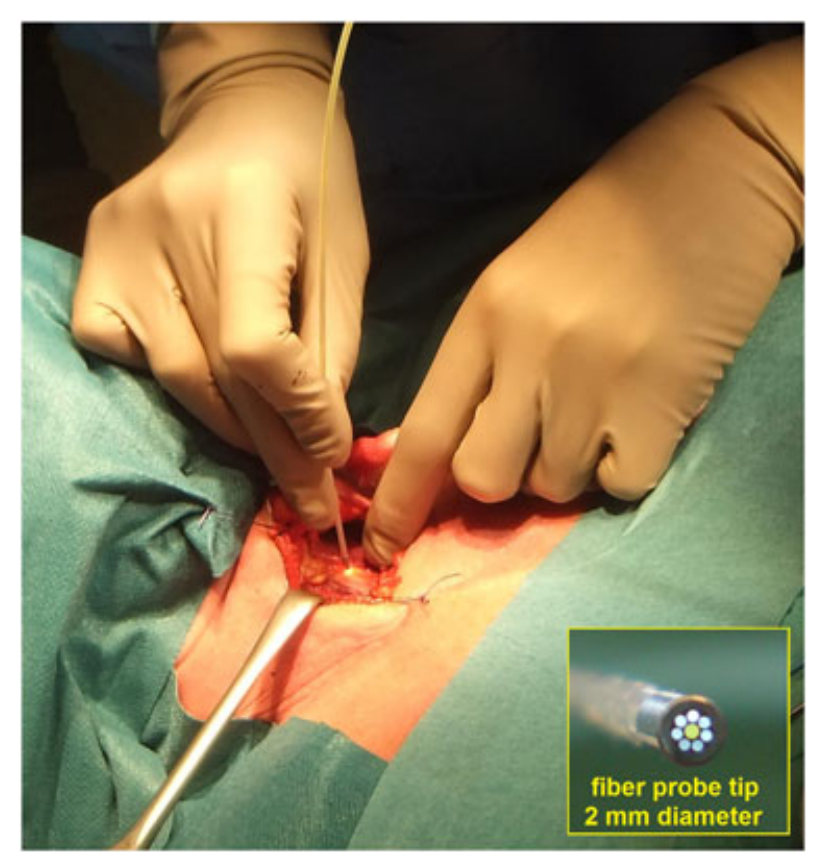

Figure 1. Intraoperative fibre probe tissue measurement. Intraoperative spectral fibre probe measurement performed during a left hemithyroidectomy procedure. The sterile optical fibre probe is gently brought into contact with one of the parathyroid glands. Right lower corner: close-up of the fibre probe tip. A ring light of seven fibres (illuminated white) injects light into the tissue, one central fibre (here for illustration purposes illuminated yellow) transports the diffusely reflected light to the spectrometer type; this resulted in 1.5 to 3 additional min per surgical procedure (see also Table 1). The sterile fibre probe was handled by the surgeon and gently brought into direct contact with one of the designated tissues (see Figure 1). If blood was visibly present on the tissue surface, it was dapped away using a sterile gauze. Between the measurements on different locations, the probe tip was swiped with a clean sterile gauze wetted with saline. Acquired data were labeled according to the tissue type description of the attending surgeon. Since extirpation of the measured 'healthy' tissue types could logically not be conducted in this explorative in vivo human study, histopathological confirmation of the measurements was not possible.

For inter-patient comparability, all raw in vivo spectra were calibrated, after the completion of in vivo spectroscopy, by using the dark current (14) and white reference phantom (Optical-grade spectralon reference; Labsphere, Inc., North Sutton, New Hampshire USA). The integration times of the silicon and InGaAs sensor were individually optimized during the Spectralon calibration. No correction for ambient light was performed.

\section{Data processing}

The calibration normalizes the radiance spectrum to yield the reflectance, which manages the problem of spectral non-uniformity of the illumination device and influence of the dark current (26). Since both reflectance intensity and spectral shape are related to the composition of the tissue, no further normalization steps were performed. To identify possible distinctive features for tissue-specific enhancement, 36 features (i.e. 18 gradients and 18 amplitude differences at predefined points in the tissue spectra) were extracted based on known wavelengths related to characteristic absorption features for blood, water and fat (27-29). Gradients are 'slopes' between two predefined points in the tissue spectra, i.e. $\left.\left(\mathrm{DR}_{2}-\mathrm{DR}\right)_{1}\right) /\left(\lambda_{2}-\lambda_{1}\right)$. Amplitude differences are 'intensity differences' between two predefined spectral points, i.e. $\left(D_{2}-\mathrm{DR}_{1}\right)$. $\mathrm{DR}=$ diffuse reflectance; $\lambda$ =wavelength. These features have also been described in our previous publication (21). Figure 2 illustrates the characteristic wavelengths and features in a mean spectrum for human adipose tissue (anatomical region: neck). All data processing was performed by in-house developed software (using MATLAB environment Version 7.7.0, MathWorks Inc., Natick, Massachusetts, USA).

To evaluate the results for application in imaging technology for identification of parathyroid within its 
Table 1. Study subject characteristics and measured sites per tissue type

\begin{tabular}{|c|c|c|c|c|c|c|c|c|}
\hline \multirow[b]{2}{*}{ Subject\# } & \multirow[b]{2}{*}{ Gender } & \multirow[b]{2}{*}{ Age } & \multirow[b]{2}{*}{ BMI } & \multirow[b]{2}{*}{ Indication for surgery } & \multirow[b]{2}{*}{ Surgical procedure } & \multicolumn{3}{|c|}{ Sites per tissue type } \\
\hline & & & & & & Thyroid & Parathyroid & Adipose \\
\hline 1 & M & 67 & 24 & Bethesda 3 * node thyroid left & Left HT & 2 & 2 & 0 \\
\hline 2 & $\mathrm{~F}$ & 55 & 32 & $\mathrm{PH}$ & Right PAR & 2 & 1 & 2 \\
\hline 3 & M & 54 & 31 & $\begin{array}{l}\text { MEN-2a syndrome, medullar } \\
\text { thyroid carcinoma left }\end{array}$ & $\begin{array}{l}\mathrm{TT}+\text { radical LND neck, } \\
\text { right axillary LND }\end{array}$ & 0 & 0 & 1 \\
\hline 4 & $\mathrm{~F}$ & 14 & 21 & $\mathrm{PH}$ & Left PAR & 2 & 2 & 2 \\
\hline 5 & $\mathrm{~F}$ & 67 & 37 & $\begin{array}{l}\text { Status after hemithyroidectomy } \\
\text { right, in which a follicular } \\
\text { carcinoma was found }\end{array}$ & $\begin{array}{l}\text { Resection of remaining } \\
\text { thyroid (left HT) }\end{array}$ & 0 & 2 & 1 \\
\hline 6 & $\mathrm{~F}$ & 53 & 34 & Multinodular goiter & $\mathrm{TT}$ & 2 & 2 & 1 \\
\hline 7 & $\mathrm{~F}$ & 56 & 44 & Bethesda 2 * node thyroid right & Right HT & 0 & 0 & 1 \\
\hline 8 & $\mathrm{~F}$ & 67 & 30 & Multinodular goiter & Left HT & 1 & 0 & 0 \\
\hline 9 & $\mathrm{~F}$ & 60 & 43 & $\begin{array}{l}\text { Tertiary hyperparathyroidism after } \\
\text { kidney transplantation }\end{array}$ & $\begin{array}{l}\text { Subtotal parathyroid } \\
\text { resection }\end{array}$ & 1 & 1 & 0 \\
\hline 10 & $\mathrm{~F}$ & 55 & - & Multinodular goiter & $\begin{array}{l}\text { Left HT + subtotal right } \\
\text { thyroidectomy }\end{array}$ & 1 & 0 & 0 \\
\hline 11 & $\mathrm{~F}$ & 50 & 18 & Multinodular goiter & Left HT & 1 & 1 & 1 \\
\hline 12 & $\mathrm{M}$ & 80 & 26 & $\mathrm{PH}$ & Left PAR & 1 & 0 & 1 \\
\hline 13 & $\mathrm{~F}$ & 54 & 35 & $\mathrm{PH}$ & Right PAR & 1 & 1 & 1 \\
\hline 14 & $\mathrm{M}$ & 74 & 29 & $\mathrm{PH}$ & Right PAR & 1 & 0 & 1 \\
\hline 15 & $\mathrm{~F}$ & 60 & 31 & Multinodular goiter & Left HT & 1 & 1 & 1 \\
\hline 16 & $\mathrm{~F}$ & 46 & 30 & Multinodular goiter & Left HT & 1 & 2 & 1 \\
\hline 17 & $\mathrm{~F}$ & 53 & 34 & $\begin{array}{l}\text { Bethesda } 3 * \\
\text { node thyroid right }\end{array}$ & Right HT & 2 & 2 & 2 \\
\hline 18 & $\mathrm{~F}$ & 23 & 23 & Graves' disease & $\mathrm{TT}$ & 2 & 2 & 1 \\
\hline \multirow[t]{3}{*}{19} & $\mathrm{~F}$ & 49 & 19 & Multinodular goiter & Left HT & 2 & 2 & 1 \\
\hline & & & & & $\begin{array}{l}\text { Sites per tissue type } \\
\text { (grand total 62) }\end{array}$ & 23 & 21 & 18 \\
\hline & & & & & $\begin{array}{l}\text { Spectra per tissue type } \\
\text { (grand total 299) }\end{array}$ & 112 & 97 & 90 \\
\hline
\end{tabular}

*The Bethesda system was used for reporting thyroid cytopathology (25).

$\mathrm{M}=$ male; $\mathrm{F}=$ female; $\mathrm{BMI}=$ body mass index; $\mathrm{PH}=$ primary hyperparathyroidism; $\mathrm{PAR}=$ parathyroid adenoma resection; $\mathrm{HT}=$ hemithyroidectomy; $\mathrm{TT}=$ total thyroidectomy; $\mathrm{LND}=$ lymph node dissection.

natural surroundings, we performed three separate classification steps: i.e. Si-sensor $(\leq 1000 \mathrm{~nm})$ features, InGaAs-sensor ( $\geq 900 \mathrm{~nm})$ features, and features covering the whole range $(350-1830 \mathrm{~nm})$. Considering the number of subjects, the number of extracted features $(\mathrm{n}=36)$ is too large to perform a statistically meaningful classification, as the extracted features could be redundant in the information they retain. Therefore, using combinations of all 36 features to build a classifier would result in a dimensionality problem and over-fitting (30). To omit this problem, we identified the most distinctive features, for classification of parathyroid in relation to surrounding adipose tissue or adjacent thyroid tissue, by using binary logistic regression (SPSS Inc., Chicago, IL, USA) for both wavelength regions separately. This statistical technique allows for the prediction of categorical dependent variables (here the tissue type: parathyroid or adipose /thyroid) using a set of independent variables (here the 36 spectral features) (31).

In accordance with our previous report on classifying nerve tissue within adipose surroundings (21), we trained a support vector machine (SVM) classifier (32) which attempts to find an optimum line to separate the training data groups with minimum risk (30). To estimate classification performance and to prevent overly optimistic results $(20,33,34)$, we implemented a crossvalidation (CV) approach. With a goal to obtain the classification accuracy as a performance measure, the data set is divided into a training set (to train the classifier) and a test set (to validate the classifier). The CV approach uses leave-one-out (LOO; in this case: leaveone-'tissue-site'-out) validation of the collected parathyroid and adipose/thyroid hyperspectral data. This approach utilizes the same data set for both training and testing purposes and is very useful in cases of a relatively small data sample.

In-house developed classifiers (using MATLAB environment Version 7.7.0, MathWorks Inc., Natick, Massachusetts, USA) were used to estimate the classification performance by calculating sensitivity, specificity, positive predictive value, negative predictive value and accuracy for both wavelength regions (i.e. Si-sensor and InGaAssensor detection range) separately and in combination. 


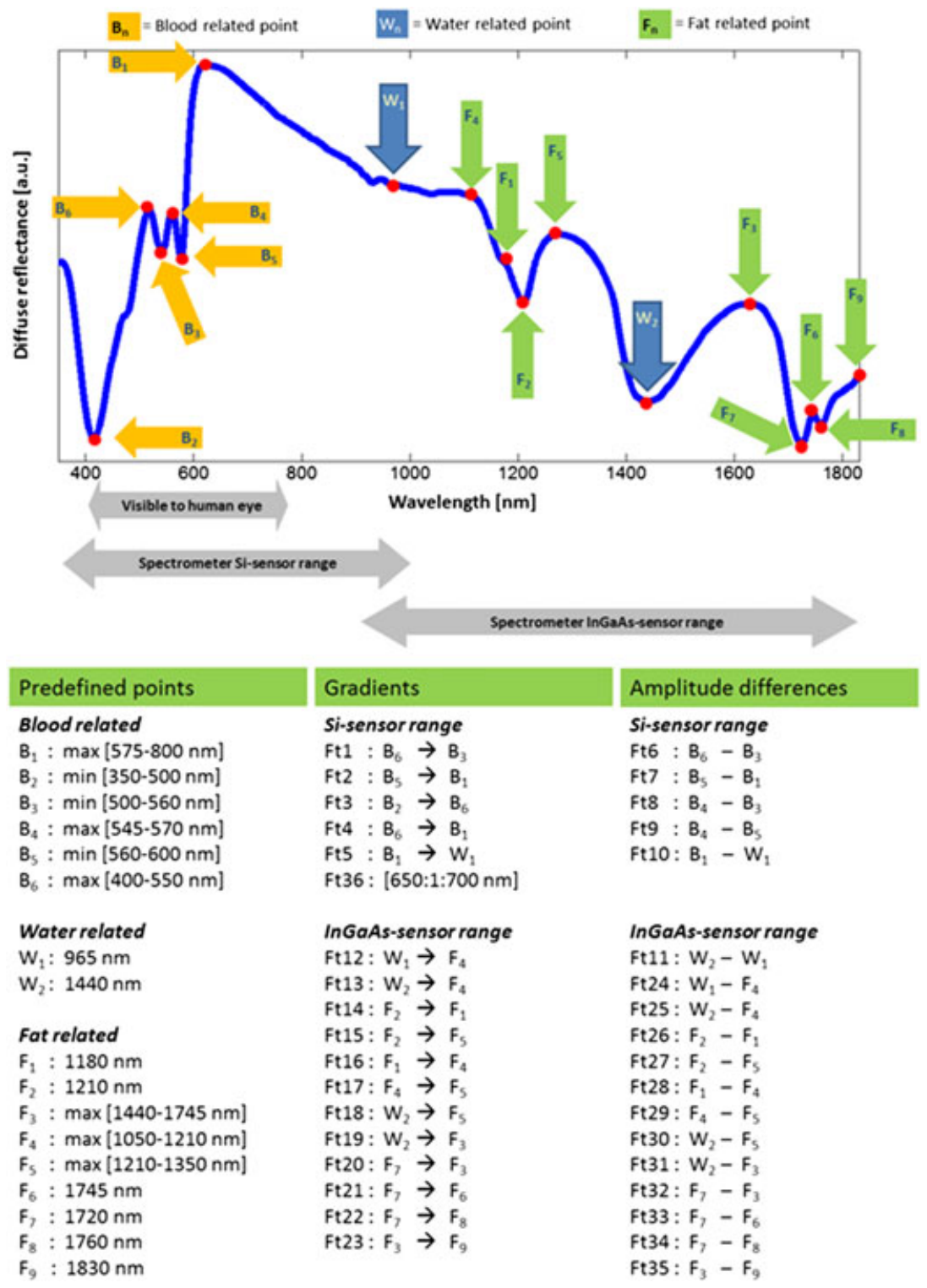

Figure 2. Example of spectrum (adipose tissue) with characteristic wavelengths and investigated features. Qualitative landmarks for oxygenated/reduced hemoglobin (characteristic 'W-shape' between 500 and $600 \mathrm{~nm}$ ), water (absorption peaks at 965 and $1440 \mathrm{~nm}$ ) and human fat (absorption peaks at 1210 and $1720 \mathrm{~nm}$ ) (27-29) are indicated by the arrows. The spectral detection ranges of respectively the human eye and of Si-sensor and InGaAs-sensor based camera chips are indicated. (This Figure was previously published as Figure 2 in: 'Differentiation between nerve and adipose tissue using wide-band $(350-1830 \mathrm{~nm})$ in vivo diffuse reflectance spectroscopy', by Schols RM, ter Laan M, Stassen LP, Bouvy ND, Amelink A, Wieringa FP, Alic L; Lasers in Surgery and Medicine, 2014 Jun 4. Epub ahead of print, doi: 10.1002/1sm.22264, (C) 2014 Wiley Periodicals, Inc. Wiley-Blackwell. Used with permission.)

\section{Results}

In 19 patients (4 male, 15 female) undergoing parathyroid or thyroid surgery, 299 in vivo tissue spectra were recorded on 62 tissue sites (thyroid $\mathrm{n}=23$, parathyroid gland $n=21$, adipose tissue $n=18$ ). Table 1 summarizes patient characteristics and the number of measured sites per tissue type. Figure 3 shows mean diffuse reflectance spectra and corresponding standard deviations for thyroid, parathyroid and surrounding adipose tissue.

\section{Classification of spectral data in Si-sensor range}

From the 36 extracted features (see Figure 2) 11 were located within the silicon detection range. Given the study sample of an average of 20 spots per tissue type, inclusion 


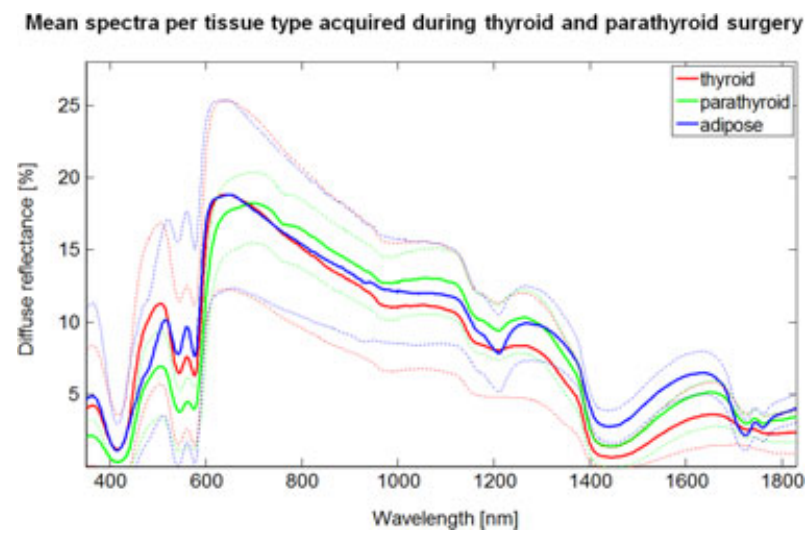

Figure 3. Mean spectra per tissue type. Average tissue spectra for thyroid (red), parathyroid (green) and adipose tissue (blue). Dashed lines in the corresponding colors indicate the respective standard deviations

of maximum 2 features is statistically responsible. Binary logistic regression identified gradients $\mathrm{Ft} 3\left(\mathrm{~B}_{2}-\mathrm{B}_{6}\right)$ and Ft36 $(650-700 \mathrm{~nm})$ as most promising combination for differentiation of parathyroid from surrounding adipose tissue. Gradient Ft36 (650-700 nm) solely, also appeared to be the best distinctive feature for differentiation of parathyroid from thyroid tissue. Figure 4(A) shows a scatter plot (Ft36 and Ft3) for classification of parathyroid in adipose surrounding. Figure 4(B) shows a boxplot (Ft 36) for classification of parathyroid in thyroid surrounding.

The quantitative results of classification performance are listed in Table 2. Leave-one-out cross-validation (LOO CV) is based on Si-sensor range data from thyroid and parathyroid surgery for train and test purposes.

\section{Classification of spectral data in InGaAs-sensor range}

From the 36 extracted features 25 were located within the spectral detection range of InGaAs (see Figure 2). After binary logistic regression, gradients $\mathrm{Ft} 12\left(\mathrm{~W}_{1}-\mathrm{F}_{4}\right)$ and Ft17 $\left(\mathrm{F}_{4}-\mathrm{F}_{5}\right)$ were selected as the most promising combination for differentiation of parathyroid from surrounding adipose tissue. Gradients Ft12 $\left(\mathrm{W}_{1}-\mathrm{F}_{4}\right)$ and Ft14 $\left(\mathrm{F}_{2}-\mathrm{F}_{1}\right)$ were identified as best distinctive feature combination for differentiation of parathyroid from thyroid tissue. Figure 5(A) and 5(B) show scatter plots for these InGaAs-sensor based features, extracted for respectively parathyroid versus adipose tissue and parathyroid versus thyroid tissue.

The quantitative results of LOO CV classification performance are listed in Table 3. LOO CV is solely based on InGaAs-sensor range data from thyroid and parathyroid surgery for train and test purposes.

\section{Combining Si-sensor and InGaAs-sensor ranges for spectral data classification}

Classification performance was also evaluated when combining the Si-sensor and InGaAs-sensor detector ranges, including up to 3 spectral features. After binary logistic regression, gradients Ft12 $\left(\mathrm{W}_{1}-\mathrm{F}_{4}\right)$, Ft17 $\left(\mathrm{F}_{4}-\mathrm{F}_{5}\right)$ and Ft36 $(650-700 \mathrm{~nm})$ were selected as the most promising combination for differentiation of parathyroid from surrounding adipose tissue.

Gradients Ft27 $\left(\mathrm{W}_{1}-\mathrm{F}_{4}\right)$ and Ft32 $\left(\mathrm{F}_{2}-\mathrm{F}_{1}\right)$ and Ft36 $(650-700 \mathrm{~nm})$ were identified as best distinctive feature combination for differentiation of parathyroid from thyroid tissue.

Figure 6(A) and 6(B) show scatter plots for these combined Si-sensor and InGaAs-sensor based features, extracted for respectively parathyroid versus adipose tissue and parathyroid versus thyroid tissue.

The quantitative results of LOO CV classification performance are listed in Table 4. LOO CV is based on the whole wide-band spectral range covering both Si-sensor and InGaAs-sensor range data from thyroid and parathyroid surgery for train and test purposes.

\section{Discussion}

The wide band (350-1830 nm) diffuse optical reflectance fingerprints of human thyroid, parathyroid and surrounding adipose tissue were identified in this explorative study. These spectra covered silicon (Si) and indium gallium arsenide (InGaAs) detector ranges, thereby exceeding wavelength boundaries $(1600 \mathrm{~nm}$ or $1700 \mathrm{~nm})$ reported by preceding work $(22,23,25,26)$. Spectroscopic measurements on human skin samples in the wavelength range 1000-2200 $\mathrm{nm}$ have previously been reported (35), but not regarding any of the tissues included in our study.

Although the presented reflectance spectra (Figure 3) show great similarity between the three different tissue types, performance of automated tissue-specific classification was fairly accurate in both sensor detection ranges (i.e. Si and InGaAs) to discriminate parathyroid tissue from either surrounding adipose tissue or adjacent thyroid tissue. Based on the classification accuracies (Tables 2 and 3) we can conclude that Si and InGaAs sensors are equally suited for automated discrimination between parathyroid glands and surrounding adipose tissue or adjacent thyroid tissue. As tissue-classification accuracies of around $80 \%$ are far from clinically relevant, we also investigated combining the two spectral sensor ranges, which resulted in improved classification performance regarding differentiation of parathyroid tissue from surrounding adipose tissue. 
A

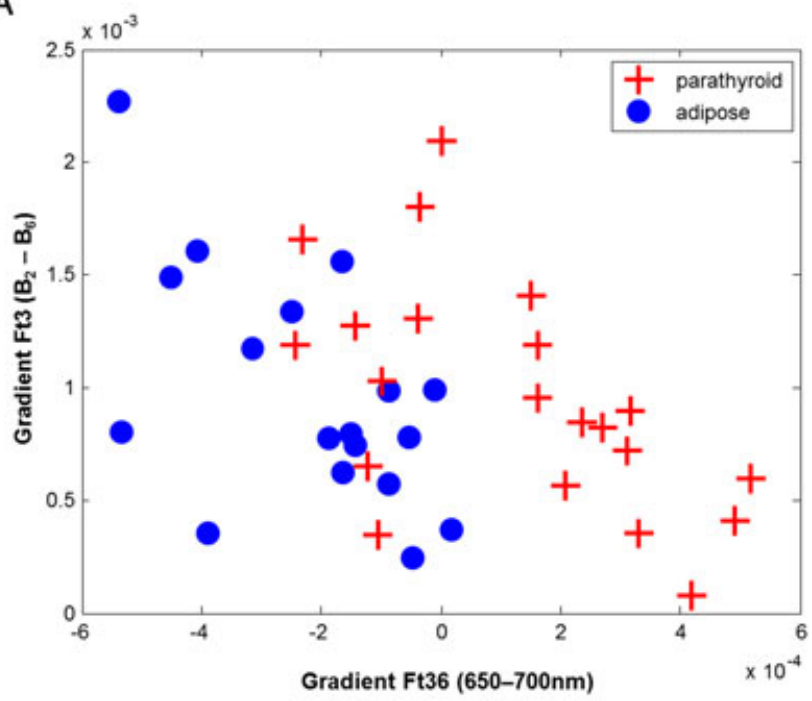

B

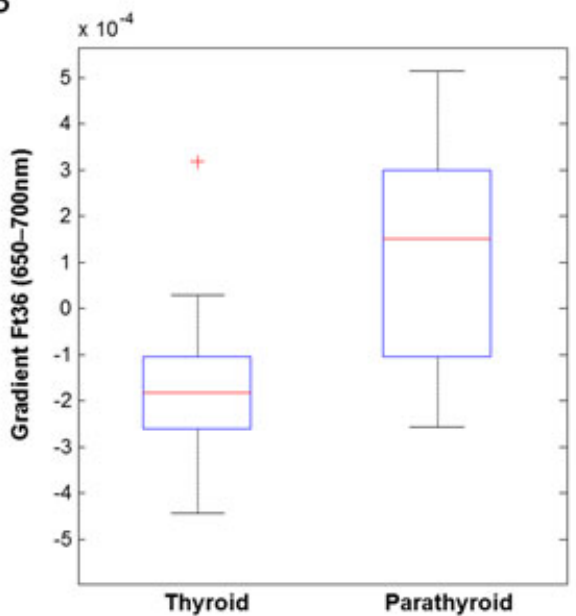

Figure 4. (A) Parathyroid versus adipose tissue: scatter plot of two selected features within Si-range. Each data point in this scatterplot represents the selected features (gradients Ft3 and Ft36) estimated using DRS data from 21 parathyroid and 18 adipose tissue sites. (B) Parathyroid versus thyroid: box plot of selected feature within Si-range. Box plot showing selected feature (gradient Ft36) estimated using DRS data from 23 thyroid and 21 parathyroid tissue sites

Table 2. Classification performance of selected Si-sensor features

\begin{tabular}{lccccccc}
\hline LOO CV & TP & TN & Sensitivity & Specificity & PPV & NPV & Accuracy \\
\hline Parathyroid - Adipose & $15 / 21$ & $16 / 18$ & $71(48-88)$ & $89(64-98)$ & $88(62-98)$ & $73(50-88)$ & 79 \\
Parathyroid - Thyroid & $15 / 21$ & $20 / 23$ & $71(48-88)$ & $87(65-97)$ & $83(58-96)$ & $77(56-90)$ & 80 \\
\hline
\end{tabular}

$\mathrm{TP}=$ true positive; $\mathrm{TN}=$ true negative $\rightarrow$ numbers indicate identified tissue spots. A positive test is defined as the tissue observed being parathyroid gland; a negative test is defined as the tissue observed being adipose tissue / thyroid.

Sensitivity; specificity; PPV = positive predictive value; NPV = negative predictive value; accuracy $\rightarrow$ numbers are percentages; numbers in parentheses indicate $95 \%$ confidence interval.

LOO CV = leave-one-out cross-validation.

Regarding the spectral signatures of the three tissue types (Figure 3) we observed a clear opposite course (i.e. ascending slope between 650 and $700 \mathrm{~nm}$ ) for parathyroid compared with the spectra of adipose tissue and thyroid (i.e. descending slope). From this, feature Ft36 was established. Another blood-related feature 
A

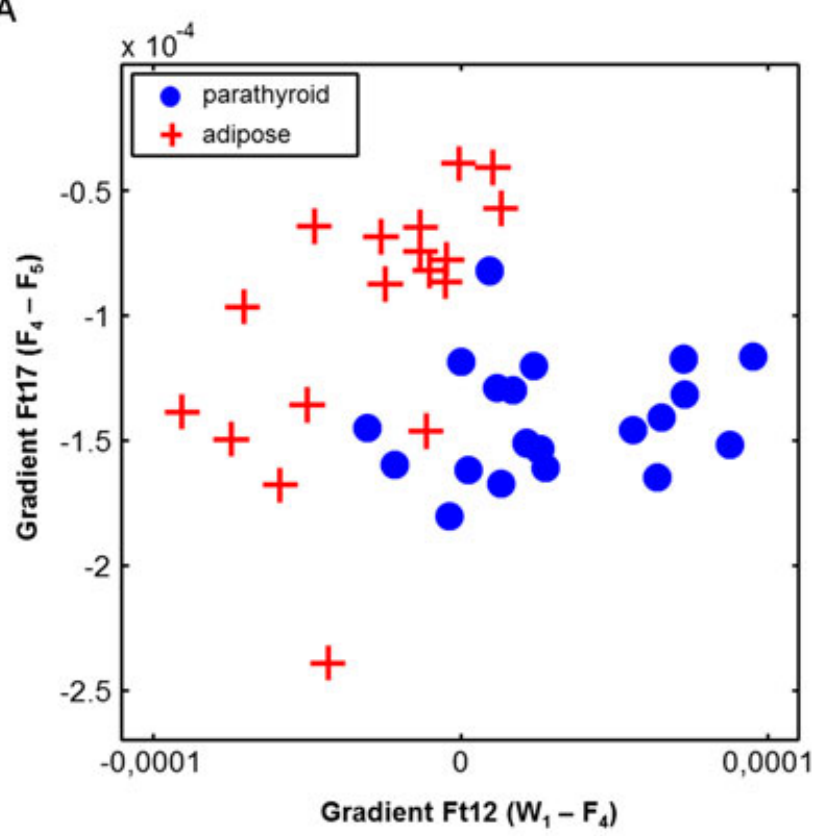

B

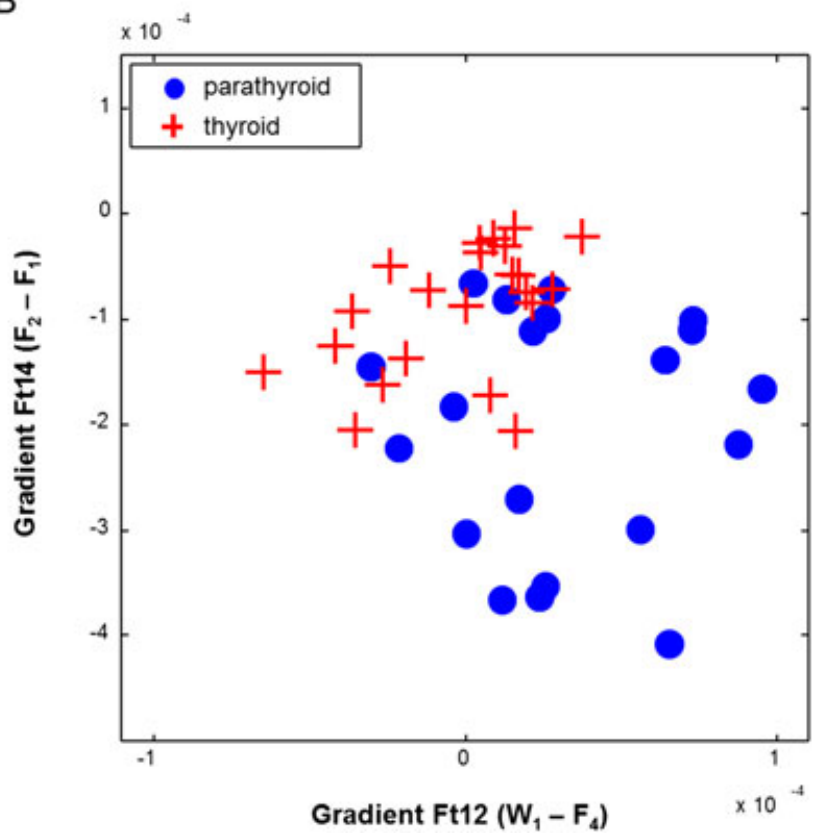

Figure 5. (A) Parathyroid versus adipose tissue: scatter plot of two selected features within InGaAs-range. Scatter plot showing two selected features (gradients Ft12 and Ft17) estimated using DRS data from 21 parathyroid and 18 adipose tissue sites. (B) Parathyroid versus thyroid tissue: scatter plot of two selected features within InGaAs-range. Scatter plot showing selected features (gradients Ft12 and Ft14) estimated using DRS data from 21 parathyroid and 23 thyroid tissue sites

(Ft3) in the Si sensor range was complementary for distinguishing parathyroid from surrounding adipose tissue (Figure 4). Within the InGaAs sensor range fatrelated features (Figure 5, respectively, Ft12 and Ft14, and Ft12 and Ft17) performed best for enabling automated tissue classification. Combining $\mathrm{Si}$ and InGaAs sensor features resulted in improved tissue classification; this was especially profound when discriminating parathyroid from adipose tissue. The statistically different spectral features used for classification of parathyroid versus adipose tissue or thyroid are probably due to differences in chemical composition (e.g. water/lipid content) of the investigated tissues and structures. 
Table 3. Classification performance of selected InGaAs-sensor features

\begin{tabular}{lccccccc}
\hline LOO CV & TP & TN & Sensitivity & Specificity & PPV & NPV & Accuracy \\
\hline Parathyroid - Adipose & $19 / 21$ & $13 / 18$ & $90(68-98)$ & $72(46-89)$ & $79(57-92)$ & $87(58-98)$ & 82 \\
Parathyroid - Thyroid & $16 / 21$ & $17 / 23$ & $76(52-91)$ & $74(51-89)$ & $73(50-88)$ & $77(54-91)$ & 75 \\
\hline
\end{tabular}

$\mathrm{TP}=$ true positive; $\mathrm{TN}=$ true negative $\rightarrow$ numbers indicate identified tissue spots. A positive test is defined as the tissue observed being parathyroid gland; a negative test is defined as the tissue observed being adipose tissue / thyroid.

Sensitivity; specificity; PPV = positive predictive value; NPV = negative predictive value; accuracy $\rightarrow$ numbers are percentages; numbers in parentheses indicate $95 \%$ confidence interval.

LOO CV = leave-one-out cross-validation.
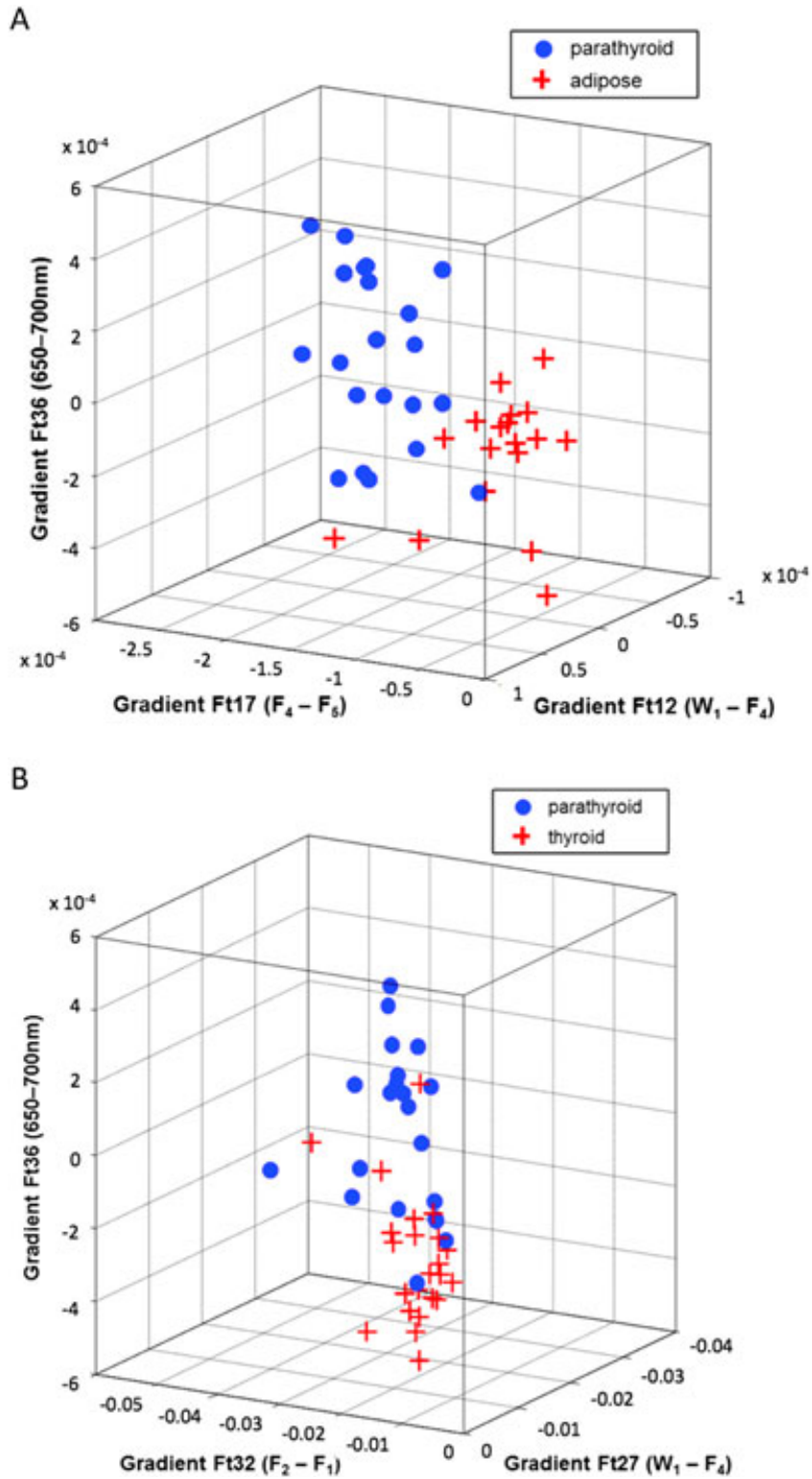

Figure 6. (A) Parathyroid versus adipose tissue: scatter plot of three selected features. Three-dimensional scatter plot showing selected features (gradients Ft12, Ft17 and Ft36) estimated using DRS data from 21 parathyroid and 18 adipose tissue sites. (B) Parathyroid versus thyroid tissue: scatter plot of three selected features. Three-dimensional scatter plot showing selected features (gradients Ft27, Ft32 and Ft36) estimated using DRS data from 21 parathyroid and 23 thyroid tissue sites 
Table 4. Classification performance of combined Si-sensor and InGaAs-sensor features

\begin{tabular}{lccccccc}
\hline LOO CV & TP & TN & Sensitivity & Specificity & PPV & NPV & Accuracy \\
\hline Parathyroid - Adipose & $21 / 21$ & $17 / 18$ & $100(81-100)$ & $94(71-100)$ & $95(75-100)$ & $100(77-100)$ & 97 \\
Parathyroid - Thyroid & $18 / 21$ & $18 / 23$ & $86(63-96)$ & $78(56-92)$ & $78(56-92)$ & $86(63-96)$ & 82 \\
\hline
\end{tabular}

$\mathrm{TP}=$ true positive; TN $=$ true negative $\rightarrow$ numbers indicate identified tissue spots. A positive test is defined as the tissue observed being parathyroid gland; a negative test is defined as the tissue observed being adipose tissue / thyroid.

Sensitivity; specificity; PPV = positive predictive value; NPV = negative predictive value; accuracy $\rightarrow$ numbers are percentages; numbers in parentheses indicate $95 \%$ confidence interval.

LOO CV = leave-one-out cross-validation.

Experimental methods such as near-infrared fluorescence imaging after peripheral infusion of aminolevulinic acid $(8,9)$ or methylene blue (10) (i.e. exogenous contrast agents) could also be used for parathyroid gland or parathyroid adenoma localization. The reflectance spectra in our study, which were the basis to extract spectral features, originate from intrinsic tissue properties (i.e. endogenous chromophores) that do not require dye administration. Consequently there is no risk of potential toxicity or allergy to a contrast agent.

As the LOO cross-validation method inherently produces relatively optimistic classification results, external validation remains essential before classification models can be implemented in clinical practice (36). Such validation would need to be performed on newly acquired data in a multi-center study.

In this study, we use physiological knowledge on composition of different tissue types, and thereby use the pre-defined spectral regions of interest covering hemoglobin, water and fat. Tissue differentiation on the basis of completely automatically extracted features from a larger data set might achieve better results, and should be explored in future work. In addition, as the acquired reflectance spectra are specific to the probe geometry, more research is needed on the relation between these reflectance spectra and in vivo intrinsic tissue biological properties, which potentially could be captured by optical tissue properties. This is needed to obtain a better understanding of the nature of discrimination performance: i.e. whether parathyroid glands can be optically distinguished from surrounding adipose tissues or adjacent thyroid tissue based on differences in light scattering behaviour (related to structural differences) or due to differences in absorption behaviour (related to chromophore concentrations such as blood, water and fat). Such an approach would also be tissue-specific and robust to inter-patient and multi-centre variability.

A restriction of this study is that histopathological confirmation of the in vivo measured tissues was not possible, since these tissues were not removed from the body. Therefore, the gold standard used in this study was the visual judgment of an experienced surgeon with a track record of over 1000 thyroid surgeries. This judgment is based on color (spectral) information, on the recognition of anatomical position as well as on spatial structure of a specific tissue, and on palpation. For our technique to add most to this judgment, it should be extended from spot-wise probe-measurements to imaging of the complete surgical field of view.

In contrast to previous ex vivo experiments using wideband diffuse reflectance spectroscopy (24), these measurements were performed during surgery. In vivo circumstances such as vascular filling and oxygenation were thus not disrupted.

Lymph node tissue was not included in this initial explorative study in the field of head and neck surgery, but certainly should be a subject of future research, as lymph node differentiation from parathyroid tissue can also be rather challenging during neck surgery.

In conclusion, in this study we have identified that $\mathrm{Si}$ and InGaAs sensors are quite accurate for automated spectroscopic classification of parathyroid glands and surrounding adipose tissue or adjacent thyroid tissue; but when applied separately not yet with clinically relevant levels of accuracy. Combination of these two sensor technologies, however, improves accuracy especially regarding parathyroid-adipose tissue classification. Note that an imaging system embodiment would provide spectral classification for each pixel, thus offering additional information about anatomical structures of the whole displayed image (which the present fibre probe spot measurements lack). Without such structural clues, also the human eye would be at loss for distinction. Hence, automated spectroscopic tissue classification in (para-)thyroid surgery seems feasible. Our next research will be to enable moving from single pixel contact mode to non-contact mode imaging. Having provided the proof that the hyperspectral imaging technique contains clinically relevant information opens a new path towards its integration in existing surgical tools like camera systems for open surgery or even endoscopes or robot-assisted systems. In addition, a clinically relevant camera system needs further development in terms of its physical size, energy consumption, total cost and operational speed. Recognizing this potential, the European Union has funded two research projects on surgical hyperspectral imaging: HELICoiD (HypErspectraL Imaging Cancer Detection) (37), and EXIST (Extended Image Sensing Technologies) (38). 


\section{Acknowledgements}

We would like to thank all medical and OR staff involved and the Department of Medical Technology from Maastricht University Medical Center for helping us to perform the clinical measurements. The results of this study were presented in part during the Endocrine Surgery session of the 21st International Congress of the European Association for Endoscopic Surgery (EAES) in Vienna, Austria. We also thank the European Union for providing the opportunity to expand our research efforts on surgical hyperspectral imaging.

\section{Conflicts of interest}

None declared.

\section{Ethical approval}

Prior to measurements, the local institutional review board of Maastricht University Medical Center (registration number METC 10-4-035) granted approval and preoperative written informed consent was obtained from all patients.

\section{References}

1. Mohebati A, Shaha AR. Anatomy of thyroid and parathyroid glands and neurovascular relations. Clin Anat 2012; 25: 19-31.

2. Christou N, Mathonnet M. Complications after total thyroidectomy. J Visc Surg 2013; 150: 249-256.

3. Lefevre JH, Tresallet C, Leenhardt L, et al. Reoperative surgery for thyroid disease. Langenbecks Arch Surg 2007; 392: 685-691.

4. Hahn LD, Hoyt C, Rimm DL, Theoharis C. Spatial spectral imaging as an adjunct to the Bethesda classification of thyroid fineneedle aspiration specimens. Cancer Cytopathol 2013; 121: 162-167.

5. Mansoor I, Zalles C, Zahid F, et al. Fine-needle aspiration of follicular adenoma versus parathyroid adenoma: the utility of multispectral imaging in differentiating lesions with subtle cytomorphologic differences. Cancer 2008; 114: 22-26.

6. Das K, Stone N, Kendall C, et al. Raman spectroscopy of parathyroid tissue pathology. Lasers Med Sci 2006; 21: 192-197.

7. Suh H, A'Amar O, Rodriguez-Diaz E, et al. Elastic lightscattering spectroscopy for discrimination of benign from malignant disease in thyroid nodules. Ann Surg Oncol 2011; 18: 1300-1305.

8. Prosst RL, Willeke F, Schroeter L, et al. Fluorescence-guided minimally invasive parathyroidectomy: a novel detection technique for parathyroid glands. Surg Endosc 2006; 20: 1488-1492.

9. Prosst RL, Weiss J, Hupp L, et al. Fluorescence-guided minimally invasive parathyroidectomy: clinical experience with a novel intraoperative detection technique for parathyroid glands. World J Surg 2010; 34: 2217-2222.

10. van der Vorst JR, Schaafsma BE, Verbeek FP, et al. Intraoperative near-infrared fluorescence imaging of parathyroid adenomas using low-dose methylene blue. Head Neck 2014; 36: 853-858.

11. Paras C, Keller M, White L, et al. Near-infrared autofluorescence for the detection of parathyroid glands. J Biomed Opt 2011; 16: 067012.

12. Ladurner R, Hallfeldt KK, Al Arabi N, et al. Optical coherence tomography as a method to identify parathyroid glands. Lasers Surg Med 2013; 45: 654-659.

13. Conti de Freitas LC, Phelan E, Liu L, et al. Optical coherence tomography imaging during thyroid and parathyroid surgery: a novel system of tissue identification and differentiation to obviate tissue resection and frozen section. Head Neck 2014; 36: 1329-1334.

14. Lu G, Fei B. Medical hyperspectral imaging: a review. $J$ Biomed Opt 2014; 19: 10901.

15. Holzer MS, Best SL, Jackson N, et al. Assessment of renal oxygenation during partial nephrectomy using hyperspectral imaging. J Urol 2011; 186: 400-404.

16. Olweny EO, Faddegon S, Best SL, et al. Renal oxygenation during robot-assisted laparoscopic partial nephrectomy: characterization using laparoscopic digital light processing hyperspectral imaging. $J$ Endourol 2013; 27: 265-269.

17. Zuzak KJ, Naik SC, Alexandrakis G, et al. Intraoperative bile duct visualization using near-infrared hyperspectral video imaging. Am J Surg 2008; 195: 491-497.

18. Wieringa FP, Mastik F, Duncker DJ, Bogers AJ. Contrast enhancement of coronary arteries in cardiac surgery: a new multispectral stereoscopic camera technique. Euro Intervention 2006; 2: 389-394.

19. Panasyuk SV, Yang S, Faller DV, et al. Medical hyperspectral imaging to facilitate residual tumor identification during surgery. Cancer Biol Ther 2007; 6: 439-446.

20. Stelzle F, Zam A, Adler W, et al. Optical nerve detection by diffuse reflectance spectroscopy for feedback controlled oral and maxillofacial laser surgery. J Transl Med 2011; 9: 20.

21. Schols RM, ter Laan M, Stassen LP, et al. Differentiation between nerve and adipose tissue using wide-band (350-1830 nm) in vivo diffuse reflectance spectroscopy. Lasers Surg Med 2014; 46: 538-545.

22. Nachabe R, Hendriks BH, Desjardins AE, et al. Estimation of lipid and water concentrations in scattering media with diffuse optical spectroscopy from 900 to $1600 \mathrm{~nm}$. J Biomed Opt 2010; 15: 037015.

23. Nachabe R, Hendriks BH, van der Voort M, et al. Estimation of biological chromophores using diffuse optical spectroscopy: benefit of extending the UV-VIS wavelength range to include 1000 to $1600 \mathrm{~nm}$. Biomed Opt Express 2010; 1: 1432-1442.

24. Schols RM, Dunias P, Wieringa FP, Stassen LP. Multispectral characterization of tissues encountered during laparoscopic colorectal surgery. Med Eng Phys 2013; 35: 1044-1050.

25. Cao Q, Zhegalova NG, Wang ST, et al. Multispectral imaging in the extended near-infrared window based on endogenous chromophores. J Biomed Opt 2013; 18: 101318.

26. Akbari H, Kosugi Y, Kojima K, Tanaka N. Blood vessel detection and artery-vein differentiation using hyperspectral imaging. Conf Proc IEEE Eng Med Biol Soc 2009; 2009: 1461-1464.

27. Zijlstra WG, Buursma A, Meeuwsen-van der Roest WP. Absorption spectra of human fetal and adult oxyhemoglobin, deoxyhemoglobin, carboxyhemoglobin, and methemoglobin. Clin Chem 1991; 37: 1633-1638.

28. Anderson RR, Farinelli W, Laubach $\mathrm{H}$, et al. Selective photothermolysis of lipid-rich tissues: a free electron laser study. Lasers Surg Med 2006; 38: 913-919.

29. Roggan A, Friebel M, Do Rschel K, et al. Optical properties of circulating human blood in the wavelength range $400-2500 \mathrm{~nm} . J$ Biomed Opt 1999; 4: 36-46.

30. Boser BE, Guyon IM, Vapnik VN. A training algorithm for optimal margin classifiers. Proceedings of the 5th Annual ACM Workshop on Computational Learning Theory, 1992: 144-1452.

31. Tabachnick BG, Fidell LS. Using Multivariate Statistics (5th edn). Allyn-Bacon: Boston, MA, 2007.

32. Mercier G, Lennon M. Support vector machines for hyperspectral image classification with spectral-based kernels. Geoscience and 
Remote Sensing Symposium, 2003 IGARSS '03 Proceedings 2003 IEEE International. 2003; 1: 288-290.

33. Stelzle F, Tangermann-Gerk K, Adler W, et al. Diffuse reflectance spectroscopy for optical soft tissue differentiation as remote feedback control for tissue-specific laser surgery. Lasers Surg Med 2010; 42: 319-325.

34. Stelzle F, Adler W, Zam A, et al. In vivo optical tissue differentiation by diffuse reflectance spectroscopy: preliminary results for tissue-specific laser surgery. Surg Innov 2012; 19: 385-393.
35. Troy TL, Thennadil SN. Optical properties of human skin in the near infrared wavelength range of 1000 to $2200 \mathrm{~nm}$. $J$ Biomed Opt 2001; 6: 167-176.

36. Bleeker SE, Moll HA, Steyerberg EW, et al. External validation is necessary in prediction research: a clinical example. $J$ Clin Epidemiol 2003; 56: 826-832.

37. http://cordis.europa.eu/project/rcn/111274_en.html (accessed 14 February 2016).

38. http://cordis.europa.eu/project/rcn/198017_en.html (accessed 14 February 2016). 